\title{
How you choose is as important as what you choose: Subjective quality of choice predicts well-being and academic performance
}

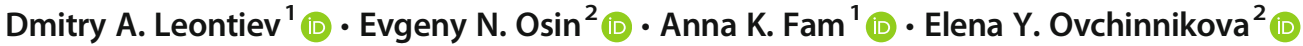

Accepted: 14 October 2020 / Published online: 25 October 2020

(C) The Author(s) 2020

\begin{abstract}
The paper proposes a new approach to measuring key parameters of choice as intentional activity. We developed and validated a 23-item questionnaire called the Subjective Quality of Choice (SQC) which measures four qualitative dimensions of choice: elaboration, emotional valence, autonomy, and satisfaction with the outcome. Three validation studies are presented. In the first study respondents from a large online sample evaluated the quality of important choices they made in life. Using structural equation modeling, we confirmed the structure of the SQC and investigated the associations of its scales with other measures. In the second study using a longitudinal design we replicated the structure of the SQC in a university choice context and investigated the criterion validity of its scales against well-being and academic outcome variables. In the third study we investigated the predictive validity of the SQC in a university applicant sample against an objective real-life outcome. The findings support the validity of the choice quality model.
\end{abstract}

Keywords Choicework $\cdot$ Subjective quality of choice $\cdot$ University entrance $\cdot$ Structure equation modeling

\section{Introduction}

The phenomenon of choice as a personal act to date does not have a stable place in psychological theory. Throughout the last century, choice was quite often reduced to decision

The datasets generated during and/or analyzed during the current study are available from the corresponding author on reasonable request.

Electronic supplementary material The online version of this article (https://doi.org/10.1007/s12144-020-01124-1) contains supplementary material, which is available to authorized users.

Dmitry A. Leontiev

dmleont@gmail.com

Evgeny N. Osin

evgeny.n.osin@gmail.com

Anna K. Fam

anna.fam@gmail.com

Elena Y. Ovchinnikova

eovchinnikova@hse.ru

1 International Laboratory of Positive Psychology of Personality and Motivation, National Research University Higher School of Economics, 20 Myasnitskaya str., 101000 Moscow, Russia

2 Department of Psychology, National Research University Higher School of Economics, Moscow, Russian Federation making, a cognitive evaluation of existing options resulting in a preferential judgment (see Simonson, 2007), though more recently we have learned that most decisions are not made in a completely rational, accountable way and that the cognitive paradigm of rational decision making has a limited scope (see e.g. Gigerenzer, 2015; Keys \& Schwartz, 2007; Peters \& Slovic, 2000). Contrary to the rationalist view, real actions may contradict the decisions made earlier in conscious judgment.

There are also multiple motivation and emotion-based alternative approaches considering psychological benefits and costs of being privileged to choose vs. no-choice condition. These focus on individual choice strategies and the emotional price of choices (Schwartz, 2004, 2012), the cultural contexts that suggest or prevent people from seeing choice options in certain situations (Iyengar, 2012; Iyengar \& Lepper, 1999; Savani, Markus, Naidu, Kumar, \& Berlia, 2010), and the effects of self-regulation processes and energy distribution in choice contexts (Baumeister, Bratslavsky, Muraven, \& Tice, 1998; Moller, Deci, \& Ryan, 2006The theories of choice in existentialist psychology and philosophy focus on the consequences of choices people make for their own lives and emphasize the transformational effects of choice (Kierkegaard, 1959; Maddi, 2012; a.o.).). It is, however, problematic to bring these and other approaches together in a sort of unified theory (see Patall, 2012). Besides, most of them conceive 
choice and resp. the lack of choice as situations in which a person finds oneself or not, as challenges to meet or benefits to make use of, rather than as something the person does more or less consciously and deliberately.

This indicates the relevance of viewing choice as an act of resolving uncertainty (associated with a multitude of possible options) in one's life. Seen this way, choice often involves decision making (construing anticipative evaluative judgments on the options), but cannot be reduced to the latter; moreover, an action may be carried out without such a judgment or go contrary to the decision. Decision making occurs in a person's mind and results in a judgment, choice happens in real life and results in an action, be it reasoned or intuitive, or in conscious abstaining from an action. Thus, choice, or choicework, is conceptualized as a form of intentional activity (Leontiev \& Pilipko, 1995), which takes place both within and beyond one's mind, and, besides cognitive accounting, also involves motivation, energy expenditure (Baumeister et al., 1998), and both external and internal mediating tools (Vygotsky, 1983). Choicework may proceed at different levels of complexity and elaboration: choosing between various brands of chewing gum or ways to spend the weekend may be quite different from choosing a spouse, a profession, or a place to live. In some cases, choice can have a sophisticated, branched, and deliberate character, in other cases, choice may be reduced to automatic unconscious operations proceeding without regard to other aspects of life and can be described by cognitive models of decision making.

At the very moment of choice its consequences are only tentatively anticipated in the future. John Locke (1690/1999) noted that the reason humans often regret the choices they have made is that they are not capable of anticipating distant and often regrettable consequences of their choices (costs) as clearly as they are anticipating the tease of immediate rewards. Hence, an existential choice cannot be "optimized": we can never be sure whether the choice we are making is the "right" one. One may, however, choose with a full awareness of one's responsibility for the choice and of the limitations concerning the predictability of its outcomes (thus, doing a "good" choicework), or one may make the choice without conscious involvement and responsibility (thus, doing a "poor" choicework, or doing without any). In the latter case, the fact of decision making (i.e. self-affirming as the one who decides) may be more subjectively important than the quality of the choice. The construct of subjective quality of choice we are introducing here refers to individual differences in the capacity to carry out a "good" choicework in a given situation. Our approach intends to analyze the phenomena described as optimal choice capacity (Schwartz, 2012) or autonomous causality orientation (Ryan \& Deci, 2017) in a specific choice context.

We are unable to present here the choicework theory at length (Leontiev, 2014; Leontiev et al., 2015). Its key assumption is that what matters is the way a choice is made, rather than what exactly is chosen in the end. Here are the main postulates of the choicework theory:

1. High-quality ("good") choicework has three related aspects: 1) elaboration (a conscious consideration of choice options (elaboration), resulting in a reflective, rather than impulsive choice); 2) autonomy (taking responsibility for one's choice and its consequences, rather than relying on someone else's opinion); 3) positive emotional experiences with respect to the choice process (a sense of confidence and ease) and in relation to its outcome (satisfaction with the resulting decision or "inner consent").

2. High-quality choicework in important life situations results in decisions that take into account the available resources and possible consequences, and are therefore more likely to lead to better objective long-term outcomes. Because such decisions also take into account the context of personality, they are also subjectively experienced as more meaningful and self-concordant, which results in sustainable intrinsic motivation and well-being (Sheldon \& Elliot, 1999).

3. The capacity to perform high-quality choicework rests on personality resources necessary to cope with the uncertainty and complexity of the choice process for extended time periods. Inability to sustain choicework may result in impulsive or premature decisions that fail to account for the consequences well enough. The list of candidate personality dispositions includes tolerance for ambiguity, self-control, hardiness, a sense of purpose, among others. Individuals with higher development of these choicework skills are expected to be able to perform more complex and elaborate choicework.

Based on the theoretical model outlined above, we attempted to identify empirically four distinct dimensions of choicework quality:

1. Choice elaboration. This cognitive dimension of choicework refers to whether the chooser approaches the challenge of making a choice with full awareness, applying the whole repertory of cognitive and metacognitive skills to construe and evaluate the available options and their consequences. High degree of choice elaboration indicates a vast cognitive processing behind the decision, whereas non-elaborate choices are made with little cognitive engagement or on impulse. In simple everyday choice situations, such as choosing daily goods in a supermarket, high elaboration may not be necessary, but in cases of important life choices it may be essential.

2. Emotional valence. This dimension of choicework refers to the degree of positivity or ambivalence of emotions experienced during the choosing process. Choices may 
be emotionally challenging, because making a decision in favor of one option implies declining the other potentially attractive ones, which may produce regret and other mixed emotions (see, e.g., Schwartz, 2004). When the preferable option is obvious from the beginning or as a result of concscious deliberation, choice might appear as an easy and pleasant process.

3. Choice autonomy. This conative dimension of the choosing process refers to the experience of agency. Many choices people make are not truly autonomous, but rather made under direct or indirect pressure with the resulting decisions experienced as controlled or enforced, rather than self-determined. We often choose something because significant others or authority figures say we must or because we follow the example of our friends when we have no definite opinion. However, the absence of agentic engagement in a choice does not typically relieve one of the responsibility for its consequences. As a result, autonomous choices, even though they require extra resources, produce more favorable psychological consequences than controlled ones (Deci \& Ryan, 2016).

4. Satisfaction with the outcome. This dimension of the quality of choicework refers to the resulting decision. Having made a choice that we may not be able to undo, we may experience it as the "right" choice or a "wrong" one, or feel uncertain about it. This evaluation of choice outcome may persist and change as we face the consequences long after the choice itself. Thus, this dimension of choice is somewhat similar to emotional valence with the difference being in their temporal scale. They may often covary, but not always: sometimes we eagerly make choices we later regret.

According to the theoretical model herein proposed, highquality choicework, or choicework of high subjective quality, feels elaborate, autonomous, emotionally positive, and results in satisfaction with the outcome. In contrast, low-quality choices can be made mindlessly (e.g., on impulse), without agentic engagement (e.g., by following external information), experienced as uneasy or unpleasant, and result in decisions that do not feel "right".

To operationalize these conceptual dimensions, we developed the Subjective Quality of Choice inventory (SQC), which starts by making an explicit reference to a specific choice the respondent has recently made. In the two subsections of the SQC the respondents are asked to evaluate the process of choice (I was/am making this choice...) and its outcome (The decision I've made was/is...) on a set of bipolar 7-point scales of semantic differential type.

We developed an initial set of 90 items and conducted a series of pilot studies (Leontiev,Mandrikova, \& Fam, 2007; Leontiev et al., 2015) to investigate its dimensionality and select the most salient items using fixed choices in realistic situations (students choosing whether to vote, newlyweds evaluating their choice of matrimonial partner) and descriptions of choice situations selected by respondents. In these initial validation studies we found a fairly invariant fourfactor structure and created a short 23-item version of the SQC (presented in Supporting Information). The studies described below had several aims: 1) to confirm the structure of the SQC in a variety of choice situations, 2) to investigate its convergent and predictive validity against choice outcomes, and 3 ) to investigate its associations with personality resources theoretically expected to form the basis for highquality choicework.

\section{Study 1. The Structure of the SQC}

\section{Aim}

The aim of the study was to confirm the structure of the 23item SQC measure using a large pool of self-reported choices and to obtain preliminary evidence of its convergent validity. More specifically, we aimed to test two postulates of the choicework theory outlined above: the association of highquality choicework with well-being outcomes, and its link to personality resources necessary to cope with uncertainty.

\section{Sample and Procedure}

Respondents were anonymous visitors to the website of the Russian edition of Psychologies magazine $(N=1833 ; 149$ male, 1684 female; average age 27.8 years, $S D=8.27$ ) who volunteered to participate in an online survey of choices to receive brief feedback on their scores.

\section{Instruments}

Respondents were asked to name and describe an important choice 'which influenced many essential aspects' of their life and to evaluate this choice using the 23-item SQC technique. The SQC items are scored from 1 to 7.

To evaluate the validity of the SQC and the choicework theory, we included two measures. First, we used Satisfaction with Life Scale (SWLS: Diener, Emmons, Larsen, \& Griffin, 1985; Osin \& Leontiev, 2020) to test the hypothesis that individuals making higher-quality choices experience higher levels of well-being (Hypothesis 1). SWLS is a 5-item instrument with a 7-point response scale. Second, we used the Multiple Stimulus Type Ambiguity Tolerance I scale (MSTAT: McLain, 1993; Leontiev, Osin, \& Lukovitskaya, 2016) to find out whether the quality of choicework is associated with personality resources necessary to cope with uncertainty (Hypothesis 2). MSTAT is a 22-item measure with a 7point response scale. 


\section{Results}

\section{Structure of the SQC}

To test the hypothesized structure of the SQC, we used Confirmatory Factor Analysis (CFA) in Mplus 8.4 with $W L S$ estimator, treating indicators as ordered categorical (Sellbom $\&$ Tellegen, 2019). We relied on the values of $C F I>.90$, and RMSEA $<.08$ as indication of acceptable model fit, interpreting these indices in combination (Brown, 2015; West, Taylor, \& Wu, 2012).

We started by testing a four-factor ESEM model (exploratory factor analysis with target rotation) to verify the assignment of items to scales. Next, we tested two principal competing models, a correlated-factor $C F A$ model with four factors and a bifactor model (see Fig. 1), where we included two additional uncorrelated factors to address the effects of item direction. We also included a correlated uniqueness for two substantially similar items, 12 and 22, belonging to the Choice Elaboration subscale and reflecting unexpected vs. expected outcome aspect of choice that is not addressed by any other items in this scale.

The ESEM model fit the data well $\left(\chi^{2}=1064.25, d f=166\right.$, $p<.001, C F I=.979, R M S E A=.054,90 \%$ CI [.051-.057]), supporting the theoretical model. All the theoretically expected factor loadings were statistically significant, moderate to high $(\lambda>.50$, with only two in the $.38-.50$ range), and exceeded the cross-loadings in magnitude. The full matrix of factor loadings in presented in Supporting Information.

The correlated-factor $C F A$ model showed acceptable fit to the data, based on the $C F I$, and marginal fit, based on the RMSEA $\left(\chi^{2}=2995.35, d f=223, p<.001, C F I=.936\right.$, $R M S E A=.082,90 \% C I[.080-.085])$. We expected that this could be due to unexplained shared variance of items, related to common item direction. The fit of the bifactor model was good, based on the $C F I$, and acceptable, based on the RMSEA $\left(\chi^{2}=2386.26, d f=200, p<.001, C F I=.950, R M S E A=.077\right.$, $90 \% C I[.074-.080])$. The parameters of the resulting model are presented in Fig. 1.

We also tested two alternative models, where instead of four substantive factors we modelled either a single factor (Choice Quality) or two dimensions, separating Choice Elaboration from Choice Experience (comprised by items belonging to the other three scales). The first model failed to converge. The fit of the second model was good, based on the $C F I$, and poor, based on the RMSEA $\left(\chi^{2}=2822.88, d f=\right.$ $205, p<.001, C F I=.940, R M S E A=.083,90 \% C I$ [.081-.086]). The chi-square difference test indicated worse
Fig. 1 Standardized parameters of the bifactor model (2) of the $S Q C$. Note. All the parameters shown are significant at $p<.05$; non-significant loadings of the two bias factors are omitted. The numbers of items correspond to the formulations given in Supporting Information

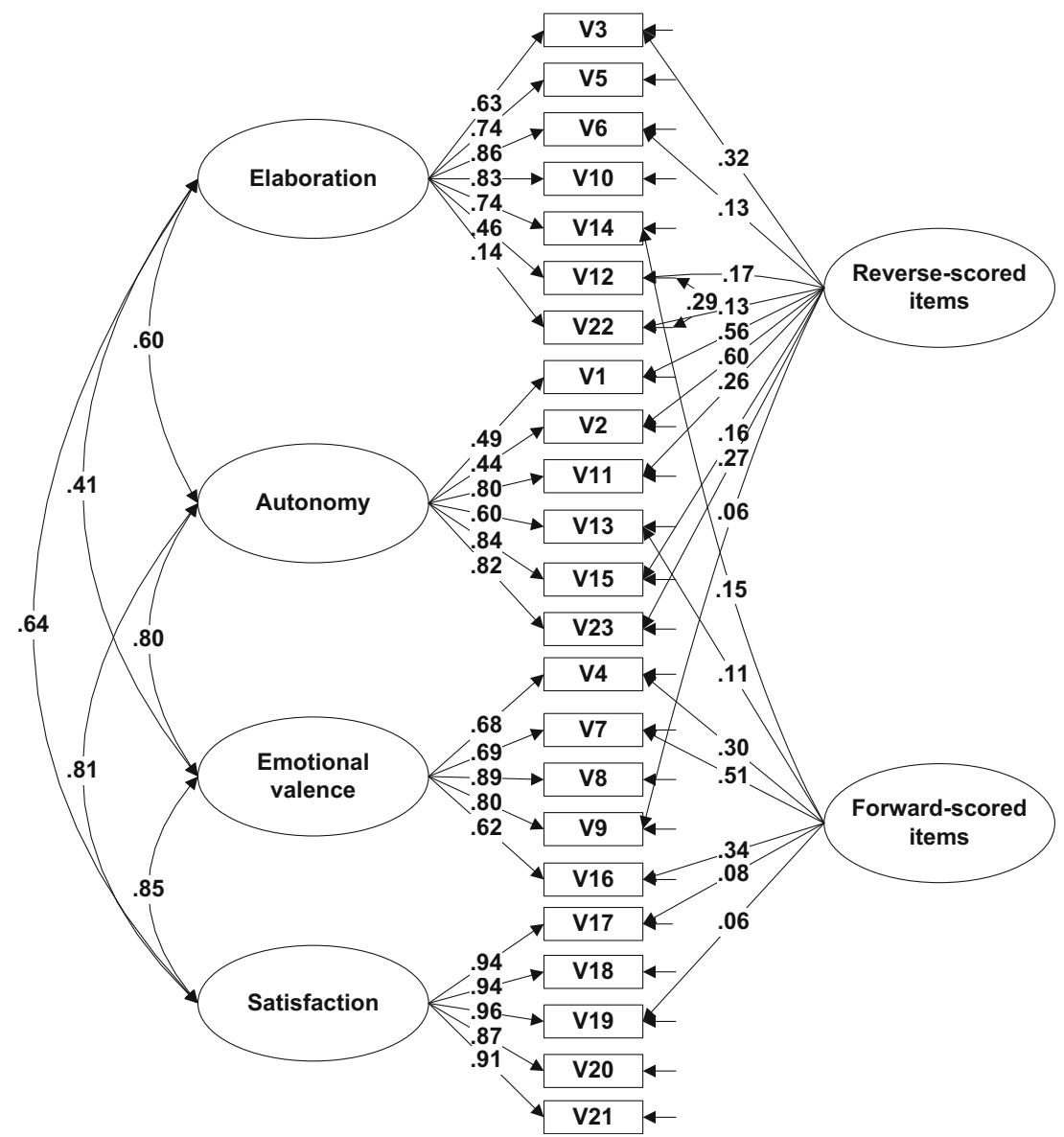


fit $\left(\Delta \chi^{2}=406.26, \Delta d f=5, p<.001\right)$, providing support for the model with four substantive factors.

\section{Correlates of Choicework Variables}

The internal consistency (Cronbach's $\alpha$ ) coefficients for the 4 SQC scales ranged between .77 and .91. The observed zeroorder correlations are presented in Table 1. All three characteristics of choicework process (elaboration, autonomy, and valence) were significantly and positively associated with the satisfaction with choice outcome. The associations of all four choicework quality characteristics with satisfaction with life and with tolerance for ambiguity were also positive and significant, in line with the theoretical expectations.

\section{Brief Discussion}

Confirmatory factor analysis has supported the hypothesized structural model. The correlations between different dimensions of choicework quality were weak to moderate, suggesting that important choices in different life domains and situations may involve different combinations of elaboration with emotional valence and autonomy: pleasant choices may not always be elaborate, and elaborate ones are not always pleasant. This is to be expected, given the vast diversity of choice situations recalled by participants in terms of recency and time scale, life domain, controllability.

However, positive correlations of choice elaboration, choice autonomy, and choice valence with satisfaction with choice outcome suggest that higher-quality choices are generally associated with more satisfying outcomes, confirming the hypothesis proposed within the choicework theory. The association of choice quality subscales with satisfaction with life further extends this finding: though the effects are not strong ( $r$ in the .15-.34 range), this is to be expected, given that the SQC only tapped into a single one of the many important choices that shape one's life course.

The associations with MSTAT indicate that individuals with higher tolerance of uncertainty tend to make more autonomous, unambiguous, and satisfying choices, though they do not always spend much more time and effort in the process. This finding confirms another expectation of the choicework theory, that the capacity to perform high-quality choicework requires personality resources essential for coping with uncertainty.

The cross-sectional design precludes from making any causal inferences: while it is plausible that well-made important choices result in higher life satisfaction, individuals with higher current levels of well-being could also be more likely to recall the choices they were satisfied with (Matt, Vázquez, \& Campbell, 1992).

Another important limitation of the study is its biased gender sample. We had not expected any effects of gender on the resulting structure and scores. The data only revealed small differences indicating higher choice autonomy $(d=.18$, $p=.037)$ and choice deliberation $(d=.20, p=.022)$ in females, as well as higher tolerance for ambiguity $(d=.29$, $p<.001)$ in males. The correlations obtained for males and females did not differ significantly, based on the $z$ test. Based on this, we treated the sample as a whole and did not focus on gender differences, due to possible sample bias.

We attempted to overcome these limitations in Study 2, using a more balanced sample of individuals in a realistic fixed choice situation and a longitudinal design to investigate the long-term consequences of choices.

\section{Study 2. Quality of University Choice as Predictor of Academic Success and Life Satisfaction}

\section{Aim and Hypotheses}

We aimed to replicate the structure of the SQC and to obtain more evidence of its convergent and predictive validity in a university choice setting. Firstly, we hypothesized that individual differences in the quality of university choices should be associated with individual differences in personality dispositions relevant for choicework (self-control, hardiness, purpose in life).

Table 1 Descriptive statistics and Pearson correlations for Study 1 scales

\begin{tabular}{|c|c|c|c|c|c|c|c|}
\hline & $\alpha$ & $M(S D)$ & Autonomy & Elaboration & Valence & Satisfaction & MSTAT \\
\hline Autonomy & .77 & $5.25(1.40)$ & & & & & \\
\hline Elaboration & .78 & $5.28(1.26)$ & .22 & & & & \\
\hline Valence & .81 & $3.38(1.50)$ & .41 & -.01 & & & \\
\hline Satisfaction & .91 & $5.01(1.67)$ & .50 & .32 & .50 & & \\
\hline MSTAT & .88 & $4.09(0.89)$ & .25 & .08 & .25 & .22 & \\
\hline SWLS & .84 & $3.93(1.27)$ & .21 & .15 & .20 & .34 & .28 \\
\hline
\end{tabular}

$N=1833$. All coefficients .08 and above are significant at $p<.001$ 
Secondly, we expected that university choices of higher quality should be associated with better academic outcomes and higher well-being both in a cross-sectional and in a long-term perspective: in countries where students only have the option to major in one discipline which must be chosen in advance of applying to a university and cannot be changed afterwards without much difficulty, making a poor initial choice of a major can easily ruin a career. We expected that students who had performed higher-quality choicework were more likely to choose a discipline in line with their passions, talents, and abilities, which should result in better adaptation at university (higher intrinsic academic motivation, academic control, academic self-efficacy, and GPA) and higher satisfaction with life.

\section{Sample and Procedure}

The sample was comprised by two cohorts of first-year Chemistry students. The first measurement occasion (Time 1) took place during the first academic year in March for Cohort 1 and in November of the same year for Cohort 2 . The second measurement occasion (Time 2) took place in March and November, respectively, a year later. The students who volunteered to participate were asked to complete a paper-based survey in class after their lectures. Informed consent procedure was used and coding was utilized to anonymize the questionnaires on receipt.

At Time 1, we obtained the responses of 156 out of 241 students comprising Cohort 1 (64.7\%) and 122 out of 255 students comprising Cohort 2 (47.8\%) resulting a combined $N=278$. Nine more students (6 and 3 in Cohorts 1 and 2, respectively) failed to provide identifiers at Time 1, but their data were used in structural analyses $(N=287)$. At Time 2 , the number of students present was 139 in Cohort 1 and 93 in Cohort 2. The number of students matched across both measurement occasions was 104 and 58, respectively, resulting in a combined $N=162$ for the longitudinal analyses.

\section{Instruments}

The SQC was administered at Time 1 with the instruction to evaluate the "choice of the university and the study programme you are in'. Three measures tapped into personality resources expected to be relevant for high-quality choicework:

Noetic Orientations Test (Leontiev, 1992), a Russian modified version of the Purpose in Life Test (Crumbaugh \& Maholick, 1967), includes 20 items rated on a 7-point scale tapping into purpose in life operationalized as the experience of meaning in everyday activities and having coherent future goals. Within choicework theory, personal meaning is expected to constitute a framework which guides the choice process by linking it to the context of personally valued life goals and priorities, resulting in more unambiguous, autonomous, and satisfying choices.
Hardiness Test (Leontiev \& Rasskazova, 2006), based on the Personal Views Survey-IIIR (Maddi \& Khoshaba, 2001), is a 24item measure of hardiness with a 4-point response scale. According to Maddi (2012), hardiness is a set of attitudes that enable a person to overcome ontological anxiety and make individualist choices that create personal meaning, rather than conformist choices that reduce anxiety, but stifle personal growth.

Brief Self-Control Scale (Gordeeva et al., 2016, 2017; Tangney, Baumeister, \& Boone, 2004), a 13-item measure with a 5-point response scale. Self-control is the ability to refrain from following impulses and to delay gratification that is supposed to help individuals withstand the challenge of choice for a more extended period of time and to resist the temptation of early closure and external pressures, leading ultimately to better choices.

We also included a number of outcome measures to find out whether students who made higher-quality choices would be better adapted to the university context:

Academic Control Scale (Perry, Hladkyj, Pekrun, \& Pelletier, 2001; Russian version by Gordeeva), an 8-item measure with a 5-point response scale tapping into the belief that the student can influence his/her academic achievement at university (as opposed to powerlessness).

Academic Self-Efficacy was measured by 3 original items with a 5-point response scale: "I believe that I am able to study successfully in my chosen direction of studies", "I believe that I am able to graduate from the university with distinction", "I believe that next year I will be able to improve my academic achievements".

Grade Point Average was drawn from the university records for the first 2 years of study. The examination sessions took place twice a year, in January and in June, each with 4 to 6 exams graded on a 4-point scale (5-excellent ... 2-fail). In case of re-sits, we used an average score across all attempts.

Academic Motivation Scale (based on Vallerand et al., 1992; Gordeeva, Sychev, \& Osin, 2014) with a 5-point response scale. As two different versions of the instrument were used for the two cohorts, we only retained the three four-item subscales with invariant item formulations.

Satisfaction with Life Scale (Diener et al., 1985; Osin \& Leontiev, 2020).

\section{Results}

\section{The Structure of the SQC}

To find out whether the structure of the SQC would replicate in a specific situation of choosing a university and a major, we performed a confirmatory factor analysis to test the same set of two models as in Study 1. We used Mplus 8.4 with WLSMV estimator, due to a smaller size of the combined sample $(N=$ 287), using DIFFTEST function to compare nested models (Brown, 2015). 
In the present sample, the correlated-factor model showed acceptable fit to the data $\left(\chi^{2}=548.26, d f=223, p<.001\right.$, $C F I=.928, R M S E A=.071,90 \%$ CI [.064-.079]). However, the fit of the bifactor model with uncorrelated item direction factors was, again, better $\left(\chi^{2}=436.94, d f=200, p<.001\right.$, $C F I=.947$, RMSEA $=.064,90 \% C I$ [.057-.072]). The parameters of this model are presented in Fig. 2. The loadings of all items on the content factors were pronounced and significant, ranging from .37 to .85 . The fit of the two alternative models was, again, significantly worse, based on scaled chi-square difference test $\left(\Delta \chi^{2}=217.95, \Delta d f=6, p<.001\right.$ for a model with a single dimension and $\Delta \chi^{2}=47.23, \Delta d f=5, p<.001$ for the one with two dimensions). Thus, the structure replicated the Study 1 findings.

The internal consistency coefficients (Cronbach's $\alpha$ ) were .66 for the Autonomy and Emotional Valence scales, .79 for the Choice Elaboration, and .85 for the Choice Satisfaction. Because of lower reliability, we used latent factor score estimates derived from the structural model for the four substantive factors to reduce the adverse effects of measurement error. The $t$ test revealed no significant differences in $S Q C$ scores between male and female students.

\section{Correlates of University Choice Quality}

First, we focused on the psychological variables associated with optimal university choice using pooled cross-sectional data from the two cohorts. The correlations of the SQC with other variables are presented in Table 2. As predicted, selfcontrol and purpose in life were positive correlates of university choice quality at the level of general dispositions. Domain-specific dispositions, academic control and academic self-efficacy, also showed positive correlations with university choice quality.

\section{Longitudinal Effects of University Choice Quality}

The zero-order correlations of choice quality indicators measured at Time 1 with criterion variables measured at Time 1 and Time 2 and presented in Table 3. The choice quality indicators measured during the first year of study showed expected associations with current and follow-up measurements of satisfaction with life, academic motivation, and GPA.

To investigate the predictive validity of SQC, we used longitudinal multiple regression to predict change (Cohen, Cohen, West, \& Aiken, 2003) in well-being, motivation, and academic achievement. The score estimates for the emotional valence of choice, choice autonomy, and satisfaction with choice in the university choice context emerged as strongly correlated ( $r$ in the .84-.92 range, as opposed to .22-.50 range in Study 1). To reduce multicollinearity and increase statistical power, we combined these three variables into a single index labelled Choice Experience, reflecting a positive emotional
Fig. 2 Standardized parameters of Model 2 in Study $2(N=287)$. Note. All the parameters shown are significant at $p<.05$; nonsignificant loadings of the two bias factors are omitted. The numbers of items correspond to the formulations given in Supporting Information

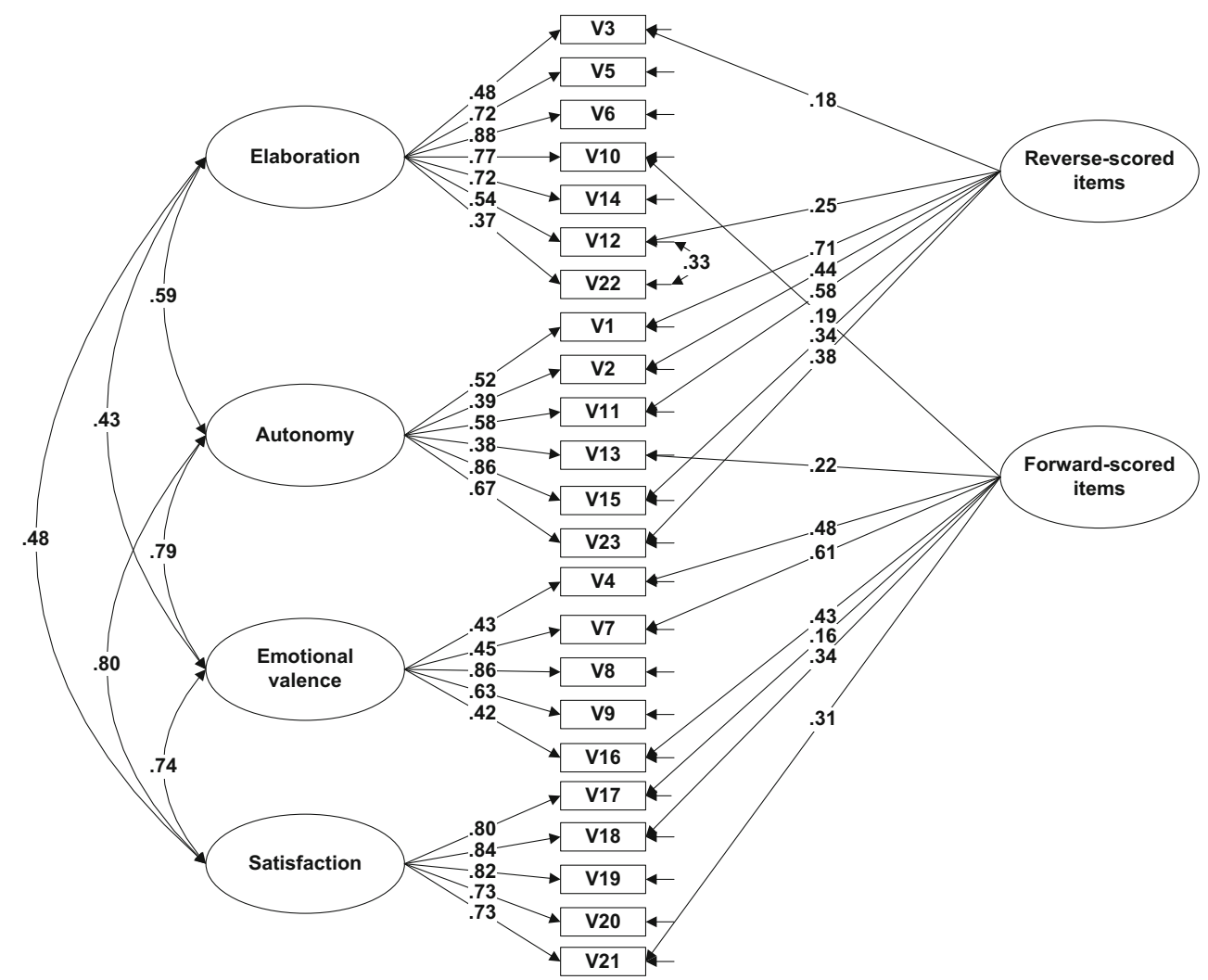


Table 2 Pearson correlations of choice quality with personality variables

\begin{tabular}{lccllll}
\hline & $N$ & $\alpha$ & Elaboration & Valence & Autonomy & Satisfaction \\
\hline Hardiness & 151 & .90 & $.17^{*}$ & $.40^{* * * *}$ & $.32^{* * * *}$ & $.44^{* * *}$ \\
Purpose in Life & 152 & .90 & $.40^{* * *}$ & $.50^{* * * *}$ & $.53^{* * * *}$ & $.55^{* * *}$ \\
Self-control & 268 & .79 & $.40^{* * *}$ & $.24 * * *$ & $.33^{* * *}$ & $.31^{* * *}$ \\
Academic control & 272 & .78 & $.35^{* * *}$ & $.27^{* * *}$ & $.35^{* * *}$ & $.36^{* * *}$ \\
Academic Self-efficacy & 273 & .66 & $.26^{* * *}$ & $.30^{* * *}$ & $.37^{* * *}$ & $.38^{* * *}$ \\
\hline
\end{tabular}

$* * * p<.001, * * p<.01, * p<.05$ experience of choice. Its correlation with Choice Elaboration was .62.

We proceeded by testing a series of regression models in Mplus 8 with $M L R$ estimator. We tested two regression models for each Time 2 dependent variable in turn. In Model 1, we controlled for pre-existing differences in DV by entering its score at Time 1 . Next, in Model 2 we entered the Time 1 Choice Elaboration and Choice Experience scores as additional predictors. We used Wald test to compare the two models. The results of these multiple regression analyses are presented in Table 4.

For Satisfaction with Life, we found a positive effect of choice experience and a negative effect of choice elaboration, indicating that university choice perceived during the freshman year as autonomous, easy, and satisfying predicts an increase in well-being from freshman to sophomore year; however, a mindful and elaborate choice that is not seen as autonomous, unambiguous, and satisfying predicts a decrease in well-being over the same period.

We also found significant effects of choice experience on the dynamics of academic motivation (significant for intrinsic motivation and amotivation and marginal for external motivation). Students who experienced their choice of university as autonomous, emotionally positive, and satisfying tended to report higher levels of intrinsic academic motivation and lower levels of external academic motivation and amotivation a year later. Controlling for choice experience, there was no specific effect of choice elaboration.

Finally, there was a positive effect of choice elaboration on the change in Grade Point Average over the first year (between the first and the second term exam sessions). There was no significant effect of SQC on the GPA change from the first to the second year. However, when we compared the groups of students who dropped out or took an extended leave from the university during the first 2 years of study $(N=$ $37)$ to those who remained at university $(N=236)$ using Student $t$ test, we found that the differences on all four SQC scales were significant, with the strongest effect for Choice Elaboration $(d=.61, p<.001)$ and Choice Autonomy $(d=.58, p<.01)$, followed by Choice Satisfaction $(d=.53$, $p<.01)$ and Emotional Valence $(d=.37, p<.05)$. The direction of all effects was the same, indicating lower choice quality in the students who dropped out. In a logistic regression with Choice Elaboration and Choice Experience as predictors of the binary dropout variable, only the effect of Choice Elaboration was significant, indicating that less elaborate university choice was associated with increased chances of dropping out $(O R=1.71, p=.038)$.
Table 3 Correlates of subjective quality of university choice at Time 1 and Time 2

\begin{tabular}{|c|c|c|c|c|c|c|}
\hline & $N$ & $\alpha$ & Elaboration & Valence & Autonomy & Satisfaction \\
\hline \multicolumn{7}{|l|}{ Time 1} \\
\hline Satisfaction with Life & 272 & .72 & $.20 * * *$ & $.26 * * *$ & $.25 * * *$ & $.28 * * *$ \\
\hline Intrinsic Motivation & 273 & .85 & $.35 * * *$ & $.50 * * *$ & $.57 * * *$ & $.58 * * *$ \\
\hline External Motivation & 273 & .74 & -.12 & $-.19 * *$ & $-.24 * * *$ & $-.22 * * *$ \\
\hline Amotivation & 273 & .85 & $-.39 * * *$ & $-.42 * * *$ & $-.52 * * *$ & $-.51 * * *$ \\
\hline GPA, Semester 1 & 262 & .67 & $.24 * * *$ & $.13^{*}$ & $.20 * *$ & $.21 * *$ \\
\hline \multicolumn{7}{|l|}{ Time 2} \\
\hline Satisfaction with Life & 154 & .81 & .09 & $.34 * * *$ & $.29 * * *$ & $.31 * * *$ \\
\hline Intrinsic Motivation & 159 & .89 & $.25 * *$ & $.40 * * *$ & $.44 * * *$ & $.46^{* * *}$ \\
\hline External Motivation & 159 & .73 & $-.20 *$ & $-.23 * *$ & $-.30 * * *$ & $-.32 * * *$ \\
\hline Amotivation & 159 & .87 & $-.34 * * *$ & $-.40 * * *$ & $-.41 * * *$ & $-.41 * * *$ \\
\hline GPA, Semester 2 & 263 & .77 & $.27 * * *$ & $.14^{*}$ & $.21 * * *$ & $.20 * *$ \\
\hline
\end{tabular}

$* * * p<.001, * * p<.01, * p<.05$ 
Table 4 The results of multiple regression analyses

\begin{tabular}{|c|c|c|c|c|c|c|}
\hline \multirow[t]{2}{*}{ Time 1 predictors } & \multirow[t]{2}{*}{$N$} & \multicolumn{2}{|c|}{ Model 1} & \multicolumn{2}{|c|}{ Model 2} & \multirow{2}{*}{$\begin{array}{l}\text { Wald test } \\
\chi^{2}(d f=2)(p)\end{array}$} \\
\hline & & $R^{2}$ & $\beta$ & $R^{2}$ & $\beta$ & \\
\hline $\begin{array}{l}\text { Satisfaction with Life } \\
\text { Choice Elaboration }\end{array}$ & 153 & $.31 *$ & $.56^{* *}$ & $.34 * * *$ & $\begin{array}{l}.53 * * * \\
-.20 * *\end{array}$ & $12.33(.002)$ \\
\hline Choice Experience & & & & & $.19 * *$ & \\
\hline $\begin{array}{l}\text { Intrinsic Motivation } \\
\text { Choice Elaboration }\end{array}$ & 159 & $.28 * * *$ & $.53 * * *$ & $.31 * * *$ & $\begin{array}{l}.43 * * * \\
-.08\end{array}$ & $7.51(.023)$ \\
\hline Choice Experience & & & & & $.22 * *$ & \\
\hline $\begin{array}{l}\text { External Motivation } \\
\text { Choice Elaboration }\end{array}$ & 159 & $.32 * * *$ & $.57 * * *$ & $.34 * * *$ & $\begin{array}{l}.54 * * * \\
-.04\end{array}$ & $5.94(.051)$ \\
\hline Choice Experience & & & & & -.13 & \\
\hline $\begin{array}{l}\text { Amotivation } \\
\text { Choice Elaboration }\end{array}$ & & & $.42 * * *$ & $.23 * *$ & $\begin{array}{l}.28 * * \\
-.06\end{array}$ & $9.84(.007)$ \\
\hline Choice Experience & 159 & $.17 * *$ & & & $-.23^{*}$ & \\
\hline $\begin{array}{l}\text { Grade Point Average } \\
\text { Choice Elaboration }\end{array}$ & 262 & $.56^{* * * *}$ & $.75 * * *$ & $.57 * * *$ & $\begin{array}{l}.72 * * * \\
.10 *\end{array}$ & $6.14(.047)$ \\
\hline Choice Experience & & & & & .01 & \\
\hline
\end{tabular}

Study 3. Quality of University Choice: Individual Patterns and Examination Success

We have investigated the structure and validity of the SQC measure in a realistic fixed situation of an important choice of a higher education programme. The results of the study support the assumptions of choicework theory.

First, we replicated the structure of the SQC and found moderate to strong associations between its dimensions, indicating that university choices that are retrospectively seen as more elaborate are also perceived as more self-determined, positive, and satisfying.

Second, we found that the self-reported quality of choicework was positively associated with personality resources theoretically expected to support sustained engagement in the choice process (self-control, hardiness) and to serve as personality structures guiding individual choices (purpose in life).

Third, we found that higher-quality choices of a university major were associated with better current and long-term academic outcomes, both objective (GPA and dropout probability) and subjective (intrinsic academic motivation, academic control, academic self-efficacy, and satisfaction with life). Students who feel having made a "good" choice of a university are more likely to remain engaged with their studies, hold constructive beliefs, and show higher and more sustained academic achievement during the freshman and sophomore years.

An important limitation of the study was the fact that the choice situation was reported retrospectively and current wellbeing levels or "recall bias" (Blome \& Augustin, 2015) may have influenced the way the experience of choice was reported by participants. To overcome this limitation, we conducted another study using the same situation in a prospective setting.

\section{Aim and Hypotheses}

We aimed to obtain evidence of predictive validity of SQC in a prospective setting by surveying university applicants who had just made their choice of a university and a major but were yet to experience its outcomes. Firstly, we expected to replicate the associations of choicework quality with personality resources (self-control, purpose in life) and well-being. Secondly, we expected that higher-quality choices would be associated with higher expectations concerning the future success at entrance exams and future studies, as well as with better subsequent objective examination outcomes: we expected that applicants who had made higher-quality choices of a study programme (i.e., carefully evaluated their interests, the value of the study programme, their chances of being admitted, etc.) would be (and would feel) more prepared for the upcoming examinations and future studies.

\section{Sample and Procedure}

The participants were university entrants applying for the psychology programme. They were approached during the 10day application period when they arrived to submit their paperwork. Leaflets were handed out in front of the application hall offering to participate in a study of individual differences predicting academic success with and receive a psychologythemed book as a reward. Informed consent procedure was used and parental consent was obtained for all participants under 18. 
The entrance examinations took place during the 2 subsequent weeks and comprised written tests on Mathematics, Language and literature, and Biology. Each work was graded on a 5-point scale and the applicants had to pass all 3 exams and receive a high cumulative score. Because of different cutoffs for full-time and part-time study, we only used the general examination outcome (accepted vs. not accepted).

The initial sample included 94 females and 18 males aged 15 to $28(M=17.06, S D=1.89)$. We excluded the data of 5 participants who failed to show up for the exams resulting in a sample size of $N=107$ (we retained the data of four participants who failed to complete some of the measures). Out of the 107 individuals who took part in the study, 34 were subsequently admitted to the university, resulting in a $31.8 \%$ success rate (compared to $14.3 \%$ according to the university statistics).

\section{Methods}

Subjective Quality of Choice We used the 23-item version with the same instruction as in Study 2.

Situational Self-Efficacy Beliefs The students were asked "How do you evaluate your chances of being admitted to the university (0-100\%)". Five other items rated on a 7-point scale tapped into the self-efficacy of entering the university (e.g., "I believe that I will pass the entrance exams successfully") and three items tapped into the self-efficacy of studying at the university (e.g., "I believe that I will have a perfect academic record at the university in the upcoming year").

Subjective Happiness Scale (Lyubomirsky \& Lepper, 1999; Osin \& Leontiev, 2020), a 4-item measure with a 7 point response scale.

We also used the same versions of Satisfaction with Life Scale (Diener et al., 1985; Osin \& Leontiev, 2020) and Noetic Orientations Test (Crumbaugh \& Maholick, 1967; Leontiev, 1992).

\section{Results}

The correlations between SQC scales and other psychological variables are given in Table 5. Choice quality showed relatively weak correlations with current satisfaction with life and current subjective happiness (consistent with the idea that choice consequences have not yet been faced by the respondents). The associations with purpose in life and self-control were similar to those found in Study 2. Choice quality was positively associated with situational self-efficacy.

The comparison of means between the successful $(N=34)$ and unsuccessful $(N=73)$ applicants is given in Table 6 . The Choice Elaboration subscale of SQC emerged as the only psychological variable significantly related to the subsequent examination outcome. In a logistic regression, a unit increase in choice elaboration was associated with a twofold increase in probability of passing the entrance exams successfully $(O R=2.11, p=.007)$.

\section{Brief Discussion}

The results of study 3 reveal the predictive validity of choicework quality in the context of entering a university, a very competitive and high-stakes situation, given that only 1 out of every 7 applicants was admitted to the programme, and that most applicants could apply to no more than two universities in one year, due to the examination schedule.

Choice elaboration was positively associated with choice autonomy and satisfaction with choice outcome, but was not significantly associated with choice valence, suggesting that elaborate choices in difficult situations with uncertain outcomes can hardly be pleasant and unambiguous. SQC showed predictable positive associations with measures of positive functioning (well-being, purpose, self-control) and success expectations. Choice elaboration emerged as not only the strongest, but also the only significant predictor of success at subsequent examinations, indicating that individuals who made this hard decision in a more elaborate, but not necessarily more independent manner, were more likely to succeed in their endeavour.

\section{General Discussion}

The combined findings of the three studies constitute the first evidence supporting the theoretical assumptions of the choicework theory, as well as structural and external validity of SQC, an assessment instrument based on the fourdimensional model of choicework. The studies used different designs (cross-sectional, longitudinal, and prospective) and settings (free choice recall vs. fixed choice situation, i.e. university choice).

The large sample used in Study 1 provided support for the structural model of SQC, which was successfully replicated in a different Study 2 setting. The subjective quality of choicework can be characterized by elaboration, valence, autonomy, and satisfaction with the outcome dimensions. The elaboration aspect of choice was somewhat more weakly related to the other three, suggesting that self-determined choices are not always made in an elaborate manner (perhaps, sometimes the "right" choice is self-evident), or that a difficult choice that requires elaboration is not always a pleasant experience.

The findings of the three studies indicate that the tendency to make high-quality choices is positively associated with personality resources theoretically expected to contribute to selfregulation during the choice process - self-control, purpose in life, tolerance for ambiguity, and hardiness. Future studies 
Table 5 Correlations of SQC with other variables

\begin{tabular}{lllllll}
\hline & $N$ & $\alpha$ & Elaboration & Valence & Autonomy & Satisfaction \\
\hline Satisfaction with Life & 106 & .72 & .14 & $.19^{*}$ & .07 & .18 \\
Subjective Happiness & 106 & .72 & .15 & $.31^{* *}$ & $.23^{*}$ & $.24^{*}$ \\
Purpose in Life & 106 & .88 & $.42^{* * *}$ & $.41^{* * *}$ & $.34^{* * *}$ & $.40^{* * *}$ \\
Self-control & 106 & .84 & $.45^{* * *}$ & .11 & $.26^{* *}$ & .14 \\
Chances (self-rating) & 102 & $\mathrm{n} / \mathrm{a}$ & $.26^{* *}$ & $.36^{* * *}$ & .13 & $.35^{* * *}$ \\
Self-efficacy of entrance & 105 & .76 & .13 & $.42^{* * *}$ & $.27^{* *}$ & $.39^{* * *}$ \\
Self-efficacy of study & 105 & .94 & $.29^{* *}$ & $.20^{*}$ & $.21^{*}$ & $.20^{*}$ \\
Elaboration & 106 & .76 & & .12 & $.28^{* *}$ & $.24^{*}$ \\
Valence & 106 & .71 & & & $.32^{* *}$ & $.64^{* * *}$ \\
Autonomy & 106 & .70 & & & & $.38^{* * *}$ \\
Satisfaction & 106 & .77 & & & & \\
\hline
\end{tabular}

$* * * p<.001, * * p<.01, * p<.05$ using quasi-experimental designs could attempt to demonstrate the causal role of these variables in shaping the choice experience. Studies 1 and 2 also showed that choice quality is positively associated with life satisfaction in a retrospective choice recall setting. It is possible, though, that retrospective evaluations of choice and of life in general might be similarly influenced by the current emotional state (Blome \& Augustin, 2015; Matt et al., 1992), which future studies could attempt to control.

Studies 2 and 3 used a prospective design to find out whether choice quality would predict future university adjustment and academic success. In Study 3, the university applicants who evaluated their choice of university as more mindful and elaborate were more likely to pass the subsequent entrance exams successfully and to be admitted to the programme of their choice. In Study 2, the first-year students who viewed their choice of a study programme as more elaborate, autonomous, and satisfying were more likely to hold

Table 6 Differences in scores of successful $(\mathrm{N}=34)$ and unsuccessful $(\mathrm{N}=73)$ applicants

\begin{tabular}{llllll}
\hline Scale & $N$ & $t$ & $d f$ & $p$ & $d$ \\
\hline Satisfaction with Life & 107 & -0.41 & 105 & n.s. & .09 \\
Subjective Happiness & 107 & -1.68 & 105 & .095 & .35 \\
Purpose in Life & 107 & -0.93 & 105 & n.s. & .20 \\
Self-control & 107 & -0.24 & 105 & n.s. & .05 \\
Chances (self-rating) & 103 & -0.91 & 101 & n.s. & .19 \\
Self-efficacy of entrance & 105 & -0.22 & 103 & n.s. & .05 \\
Self-efficacy of study & 105 & -0.38 & 103 & n.s. & .08 \\
Elaboration & 106 & -2.83 & 105 & .006 & .60 \\
Valence & 106 & 0.38 & 105 & n.s. & -.08 \\
Autonomy & 106 & 0.28 & 105 & n.s. & -.06 \\
Satisfaction & 106 & -1.19 & 105 & n.s. & .25 \\
\hline
\end{tabular}

constructive beliefs regarding their studies (academic control and self-efficacy) and to maintain higher well-being, more productive academic motivation, and higher levels of academic achievement during the first two years. In contrast, students who reported having performed lower-quality choicework were more likely to drop out from their studies during the first two years. These effects on prospective subjective and objective indicators strongly suggest that a high-quality choice is much more likely to be "right" choice, ultimately leading to higher success and well-being.

Controlling for shared variance in multiple regression, the Choice Elaboration and the three other subscales of SQC showed somewhat different effects on these outcome variables. Choice Experience mostly predicted well-being and productive motivational orientations, whereas Choice Elaboration emerged as the only predictor of subsequent objective examination success and long-term GPA. This finding suggests potentially different cognitive and emotional mechanisms behind these associations: elaboration might be more likely to involve cognitive accounting of resources and prospective difficulties resulting in better preparation, whereas choice autonomy, valence, and satisfaction might reflect subjective identification with one's choice and its integration with one's deeply held personal priorities. Overall, our results are in line with recent findings in Self-Determination Theory showing that simply reflecting on one's motivation before choosing a goal leads to choosing more self-concordant and satisfying goals that are more likely to be attained (Sheldon, 2014; Sheldon, Prentice, \& Osin, 2019). The choicework theory helps to elucidate this process further.

The present findings constitute only the first step in the development and validation of the choicework quality measure. The data show that the effects of Choice Elaboration and those of the other three scales are quite different. However, the discriminant validity of Choice Autonomy, Choice Valence, and Choice Satisfaction is not as readily evident in a university 
choice setting, where these three scales tend to covary more strongly, compared to other situations involving choices of different types and importance, according to our data. Future research could investigate the divergent validity of SQC scales against measures of maximizing-satisficing, deliberative vs. intuitive decision making, and rational vs. emotional decision making. Finally, an important limitation of the SQC approach is that retrospective evaluations of choices may undergo cognitive distortions. This issue is also worth investigation in future studies.

Acknowledgments The authors are grateful to Kennon M. Sheldon and Martin F. Lynch for their insightful comments.

Funding Data collection has been implemented by the authors on their own initiative without any funding sources. The paper was prepared within the framework of the HSE University Basic Research Program and funded by the Russian Academic Excellence Project '5-100'.

\section{Compliance with Ethical Standards}

Disclosure of Potential Conflicts of Interest The authors declare that they have no conflict of interest.

Research Involving Human Participants and/or Animals All procedures performed in studies involving human participants were in accordance with the 1964 Helsinki declaration and its later amendments or comparable ethical standards.

Informed Consent Informed consent was obtained from all individual participants included in the study.

Open Access This article is licensed under a Creative Commons Attribution 4.0 International License, which permits use, sharing, adaptation, distribution and reproduction in any medium or format, as long as you give appropriate credit to the original author(s) and the source, provide a link to the Creative Commons licence, and indicate if changes were made. The images or other third party material in this article are included in the article's Creative Commons licence, unless indicated otherwise in a credit line to the material. If material is not included in the article's Creative Commons licence and your intended use is not permitted by statutory regulation or exceeds the permitted use, you will need to obtain permission directly from the copyright holder. To view a copy of this licence, visit http://creativecommons.org/licenses/by/4.0/.

\section{References}

Baumeister, R. F., Bratslavsky, E., Muraven, M., \& Tice, D. M. (1998). Ego depletion: Is the active self a limited resource? Journal of Personality and Social Psychology, 1(74), 1252-1265. https://doi. org/10.1037/0022-3514.74.5.1252.

Blome, C., \& Augustin, M. (2015). Measuring change in quality of life: Bias in prospective and retrospective evaluation. Value in Health, 18, 110-115. https://doi.org/10.1016/j.jval.2014.10.007.

Brown, T. A. (2015). Confirmatory factor analysis for applied research (2nd ed.). N.Y: The Guilford Press.
Cohen, J., Cohen, P., West, S. G., \& Aiken, L. S. (2003). Applied multiple regression / correlation analysis for the behavioral sciences (3rd ed.). Mahwah, NJ: Lawrence Erlbaum.

Crumbaugh, J. C., \& Maholick, L. T. (1967). An experimental study in existentialism: The psychometric approach to Frankl's concept of noogenic neurosis. In V. E. Frankl (Ed.), Psychotherapy and existentialism (pp. 183-197). New York, NY: Washington Square Press.

Deci, E. L., \& Ryan, R. M. (2016). Optimizing students' motivation in the era of testing and pressure: A self-determination theory perspective. In J. Wang, C. W. Liu, \& R. M. Ryan (Eds.), Building autonomous learners: Research and practical perspectives using selfdetermination theory (pp. 9-29). Singapore: Springer. https://doi. org/10.1007/978-981-287-630-0_2.

Diener, E., Emmons, R. A., Larsen, R. J., \& Griffin, S. (1985). The satisfaction with life scale. Journal of Personality Assessment, 49, 71-75. https://doi.org/10.1207/s15327752jpa4901_13.

Gigerenzer, G. (2015). Risk savvy: How to make good decisions. New York (NY): Penguin.

Gordeeva, T. O., Osin, E. N., Suchkov, D. D., Ivanova, T. Y., Sychev, O. A., \& Bobrov, V. V. (2017). Self-control as a personal resource: Determining its relationships to success, perseverance, and well-being. Russian Education and Society, 59(5-6), 231-255. https://doi. org/10.1080/10609393.2017.1408367.

Gordeeva, T. O., Osin, E. N., Suchkov, D. D., Ivanova, T. Y., Sychev, O. A., \& Bobrov, V. V. (2016). Self-control as a personality resource: Assessment and associations with performance, persistence, and well-being [Samokontrol kak resurs lichnosti: Diagnostika I svyazi s uspeshnost'yu, nastoychivost'yu i blagopoluchiem]. CulturalHistorical Psychology [Kulturno-Istoricheskaya Psykhologiya], 12, 46-58. https://doi.org/10.17759/chp.2016120205.

Gordeeva, T. O., Sychev, O. A., \& Osin, E. N. (2014). Oprosnik "Shkaly akademicheskoi motivacii" [the "academic motivation scales" questionnaire]. Psikhologicheskii Zhurnal [Psychological Journal], 35, 96-107.

Iyengar, S. (2012). The art of choosing. London: Abbacus.

Iyengar, S. S., \& Lepper, M. R. (1999). Rethinking the value of choice: A cultural perspective on intrinsic motivation. Journal of Personality and Social Psychology, 76, 349-366. https://doi.org/10.1037/00223514.76.3.349.

Keys, D. J., \& Schwartz, B. (2007). "Leaky” rationality: How research on behavioral decision making challenges normative standards of rationality. Perspectives on Psychological Science, 2, 162-180. https:// doi.org/10.1111/j.1745-6916.2007.00035.x.

Kierkegaard, S. (1959). Either/Or. Volume I. Princeton, NJ: Princeton University Press.

Leontiev, D. A. (1992). Test snyslojiznennykh orientatsiy (SJO) [noetic orientations test (NOT)]. Moscow: Smysl.

Leontiev, D. A. (2014). Psikhologiya vybora. Chast I. Za predelami ratsionalnosti [Psychology of choice. Part I. Beyond the rationality]. Psikhologicheskiy Zhurnal [Psychological Journal], 35, 5-18.

Leontiev, D. A., Mandrikova, E. Y., \& Fam, A. K. (2007). Razrabotka metodiki diagnostiki protsessualnoy storony vybora [Development of a method of assessment\&nbsp;of processual aspects of choice]. Psikhologicheskaya Diagnostika [Psychological Diagnostics], 6, 425.

Leontiev, D. A., Mandrikova, E. Y., Rasskazova, E. I., \& Fam, A. K. (2015). Psikhologiya vybora [Psychology of choice]. Moscow: Smysl.

Leontiev, D. A., \& Pilipko, N. V. (1995). Vybor kak deyatelnost: lichnostnye determinanty i vozmozhnosti formirovaniya [Choice as activity: Its personality\&nbsp;determinants and possibilities of training]. Voprosy Psikhologii [Issues of Psychology], 1, 97-110.

Leontiev, D. A., Osin, E. N., \& Lukovitskaya, E. G. (2016). Diagnostika tolerantnosti k neopredelyonnosti: Shkaly D. Makleyna [diagnostics of ambiguity tolerance: D. McLain's scales]. Moscow: Smysl. 
Leontiev, D. A., \& Rasskazova, E. I. (2006). Test zhiznestoykosti [hardiness test]. Moscow: Smysl.

Locke, J. (1999). An essay concerning human understanding (first published 1690). Philadelphia, PA: The Pennsylvania State University.

Lyubomirsky, S., \& Lepper, H. (1999). A measure of subjective happiness: Preliminary reliability and construct validation. Social Indicators Research, 46, 137-155. https://doi.org/10.1023/A: 1006824100041

Maddi, S. R. (2012). Creating meaning through making decisions. In P. T. P. Wong (Ed.), The human quest for meaning: Theories, research, and applications (p. 57-80). Routledge/Taylor \& Francis Group.

Maddi, S. R., \& Khoshaba, D. M. (2001). Personal views survey III-R: Test development and internet instruction manual. Newport Beach, CA: Hardiness Institute.

Matt, G. E., Vázquez, C., \& Campbell, W. K. (1992). Mood-congruent recall of affectively toned stimuli: A meta-analytic review. Clinical Psychology Review, 12, 227-255. https://doi.org/10.1016/02727358(92)90116-P.

McLain, D. L. (1993). The MSTAT-I: A new measure of an individual's tolerance for ambiguity. Educational and Psychological Measurement, 53, 183-189. https://doi.org/10.1177/ 0013164493053001020.

Moller, A., Deci, E. L., \& Ryan, R. M. (2006). Choice and ego-depletion: The moderating role of autonomy. Personality and Social Psychology Bulletin, 32, 1024-1036. https://doi.org/10.1177/ 0146167206288008.

Osin, E. N., \& Leontiev, D. A. (2020). Kratkie russkoyazychnye shkaly diagnostiki subyektivnogo blagopoluchiya: Psikhometricheskie kharakteristiki i sravnitel'nyi analiz [brief Russian-language instruments to measure subjective well-being: Psychometric properties and comparative analysis]. Monitoring Obshchestvennogo Mneniya: Ekonomicheskie i Sotsial'nye Peremeny, 1, 117-142. https://doi.org/10.14515/monitoring.2020.1.06.

Patall, E. A. (2012). The motivational complexity of choosing: A review of theory and research. In R. Ryan (Ed.), The Oxford handbook of human motivation (pp. 248-279). New York (NY): Oxford University Press.

Perry, R. P., Hladkyj, S., Pekrun, R. H., \& Pelletier, S. T. (2001). Academic control and action control in the academic achievement of students: A longitudinal field study of self-regulation. Journal of Educational Psychology, 93, 776-789. https://doi.org/10.1037/ 0022-0663.93.4.776.

Peters, E., \& Slovic, P. (2000). Two springs of action: Affective and analytical information processing in choice. Personality and Social Psychology Bulletin, 26, 1465-1475. https://doi.org/10.1177/ 01461672002612002.

Ryan, R. M., \& Deci, E. L. (2017). Self-determination theory: Basic psychological needs in motivation, development, and wellness. New York, NY: The Guilford Press.
Savani, K., Markus, H. R., Naidu, N. V. R., Kumar, S., \& Berlia, N. (2010). What counts as a choice? U.S. Americans are more likely than Indians to construe actions as choices. Psychological Science, 21, 391-398. https://doi.org/10.1177/0956797609359908.

Schwartz, B. (2004). The paradox of choice: Why more is less. New York, NY: Ecco Press.

Schwartz, B. (2012). Choice, freedom, and autonomy. In P. R. Shaver \& M. Mikulincer (Eds.), Meaning, mortality, and choice: The social psychology of existential concerns (pp. 271-287). Washington, DC: APA.

Sellbom, M., \& Tellegen, A. (2019). Factor analysis in psychological assessment research: Common pitfalls and recommendations. Psychological Assessment, 31, 1428-1441. https://doi.org/10. $1037 /$ pas0000623.

Sheldon, K. M. (2014). Becoming oneself: The central role of selfconcordant goal selection. Personality and Social Psychology Review, 18, 349-365. https://doi.org/10.1177/1088868314538549.

Sheldon, K. M., \& Elliot, A. J. (1999). Goal striving, need satisfaction, and longitudinal well-being: The self-concordance model. Journal of Personality and Social Psychology, 76, 482-497. https://doi.org/ 10.1037/0022-3514.76.3.482.

Sheldon, K. M., Prentice, M., \& Osin, E. (2019). Rightly crossing the Rubicon: Evaluating goal self-concordance prior to selection helps people choose more intrinsic goals. Journal of Research in Personality, 79, 119-129. https://doi.org/10.1016/j.jrp.2019.03. 001.

Simonson, I. (2007). Decision making. In R. F. Baumeister \& K. D. Vohs (Eds.), Encyclopedia of social psychology. SAGE Publications. https://doi.org/10.4135/9781412956253.n135.

Tangney, J. P., Baumeister, R. F., \& Boone, A. L. (2004). High selfcontrol predicts good adjustment, less pathology, better grades, and interpersonal success. Journal of Personality, 72, 271-322. https://doi.org/10.1111/j.0022-3506.2004.00263.x.

Vallerand, R. J., Pelletier, L. G., Blais, M. R., Briere, N. M., Senecal, C., \& Vallieres, E. F. (1992). The academic motivation scale: A measure of intrinsic, extrinsic and amotivation in education. Educational and Psychological Measurement, 52, 1003-1017. https://doi.org/ 10.1177/0013164492052004025.

Vygotsky, L. S. (1983). Istoriya razvitiya vysshikh psikhicheskikh funktsii [history of development of higher mental functions]. In Sobranie Sochineniy [Collected Works], 3, 5-328. Moscow: Pedagogika.

West, S. G., Taylor, A. B., \& Wu, W. (2012). Model fit and model selection in structural equation modeling. In R. H. Hoyle (Ed.), Handbook of structural equation modeling (pp. 209-231). New York, NY: The Guilford Press.

Publisher's Note Springer Nature remains neutral with regard to jurisdictional claims in published maps and institutional affiliations. 